\title{
Study on Regional Design of Public Street Facilities in Tourism Areas
}

\author{
Pingqing Zhang \\ Yantai Nanshan University \\ Yantai, Shandong, China 265713
}

\author{
Yang Wang \\ Yantai Nanshan University \\ Yantai, Shandong, China 265713
}

\begin{abstract}
With the progress of social civilization, people in city are paying more and more attention to public street facilities related to human scale. There are only a few comprehensive regional researches in public street facilities of tourism areas. We don't put enough care on it. The impact of regional character on public street facilities in tourism areas also doesn't get recognition and attention in a wide range. Meanwhile, our attention and protection on regional features of public street facilities are far from enough. The paper is expected to provide a meaningful reference for the current domestic regional research of public street facilities through the comprehensive study on the regional design of public street facilities in tourism areas.
\end{abstract}

Keywords-tourism areas; public street facilities; regional features; city image

\section{INTRODUCTION}

Today, the research on public street facilities is more focused on its specific functions. We are relatively lack of attention on its location, such as the specific geographical environment of the tourism areas. The appearance and existence of this situation may result that we use same design standards to different regional environments, cultural characteristics and life styles of the public in the practical design of public street facilities. We lack intensive analysis, discussion and understanding on specific public space, geographical environment and humanistic characteristics. The regional features and the extension of background culture of the tourism scenic spot are gradually buried, and local characteristics also gradually fade away, even disappear. Features of city image are copied at will. City image is serious damaged and impacted. These updates and breakthrough have brought such a heavy price. Many cities are pursuing and building modern high buildings and large mansions, and manmade artificial attractions. Even they deliberately build "Antique Street". Such behaviors are really lack of comprehensive considerations. It is because of the frequent appearance of such phenomena, deliberate passing on and expansion, a lot of modern cities lost their regional features and the image characteristics. The tourism area of a city is a miniature of the city's characteristic landscape. Once the characteristics of the city are impacted, the tourism area in this specific environment will also be affected. Tourism area is an important part in the development of a city. Its role and special meaning decide its irreplaceable place, so we should perfect, update and comprehensively manage the public street facilities of a tourism area on condition that we respect it and protect it.

\section{THE RELATIONSHIP BETWEEN TOURISM AREAS AND Public STREet FACILITIES}

\section{A. Tourism Areas and Public Street Facilities}

Tourism area generally refers to the regional units composed by a number of geographically connected tourism attractions, transportation network and tourism service facilities of same characteristics. In a broad sense, any place that can be used by tourists or visitors to visit or carry out leisure activities can become a tourism area. With sceneries, natural landscape or artificial landscape as main carriers to attract tourists, the tourism area is a geographical space formed by many relatively small spots that can be visited by tourists and visitors, and provide a series of leisure activities. The public street facilities refer to the service facilities in public place in order to better facilitate the people for outdoor life healthily, comfortably and conveniently. The public street facility echoes with environmental characteristics with its form, spot, setoff and highlighting.

Many types of public street facilities constitute a complete system. The public street facilities jointly shoulder the responsibility to service the city. At the same time these public street facilities are also a separate system. They need to meet the needs of their hierarchical relationship, so we should carry out unified, reasonable planning and comprehensively detailed arrangement on public street facilities. The public street facility is a part of scenic spot environment. If we want to know the whole region, we need to analyze the individuals within the region. Public street facilities have characteristics of certain overall absorption and containment, so we shall coordinate the relationship of individual public street facility and the tourism area in such a specific environment and stimulate the development motivation of overall environment, reflect relatively high existence value of tourism area and its economic benefits to adapt to the development of modern cities.

\section{B. The Relationship between Tourism Area and Public Street Facilities}

The existence of public street facilities in the special space environment of tourism area is not isolated. It is mutually associated with the surrounding space environment. Tourism area should provide enough space for tourists in all aspects. It especially should give full consideration to the psychological and physiological factors of vulnerable groups, the disabled, 
the elderly, women and children, to create a convenient and comfortable public space environment, conducive to close interaction between man and man, man and nature. As a part of open public space, the street public facilities have the characteristics of continuous development and improvement, and could be coordinated with overall environment, so it has the role to balance the spatial relationship. The spatial environment formed by the public street facilities directly affects the tourist activities in scenic spot, and the related surrounding environment, so it has the function to connect each small space environments. Public street facility is a kind of social public resource, and an integral part to support the large system of city. The setting of public street facilities needs to adapt to and coordinate with functions of city, and build a powerful aura to meet the needs of the harmonious development of the city. The wholeness and systematic design of public street facilities can enhance the connotation and grade of scenic spot environment, at same time provide a reference standard for the future development of the scenic spot environment. The street public facilities with regional features can endow tourism spots with affinity, and enrich the environment content of tourism area.

The relationship between public street facilities and tourism area is complement and mutually promoted. The tourism area with complete public street facilities can attract more visitors, and make activities more active. At same time visitors and tourists could give good suggestions in designing public street facilities. The public street facility is a part of tourism area, and it also is a part of its environment planning. Thus, the public street facility should be harmonious with the specific environment. It should reflect the cultural connotation of scenic spots, but also make the scenic spot environment more beautiful and attractive.

\section{The Significance and Importance of Public Street Facilities in Tourism Area}

The public street facilities in tourism area have distinct characteristics of individual object, but they appear in specific environment in the form of entity and even integrate together with the space environment of whole city. Tourism area is relatively an open social public space, and the setting range of public street facilities is also in a relatively open environment.

- The public street facilities can provide corresponding services for the tourism area and set off the unique characteristics of the tourism area by contrast. Above all, it echoes with the environment facilities within tourism area. It can avoid complicated and unnecessary repeated construction. It can prevent other units in tourism area distracting attentions of tourists, to guide tourists with pubic street facilities, so that the whole scenic spot is of no difference between primary and secondary, and the spatial layering of the tourism area could be reflected clearly. The public street facilities can improve the scenic environment, enhance benign loop of public space, meanwhile, also perfect environment facilities to meet people's needs and provide good environment for various activities.
- The public street facilities within tourism areas are auxiliary facilities closely linked with our outdoor life. The public street facility design is a product design in public space and gradually perfected with the development of city. Its existence, like other buildings, may change with the development of human and follow the requirements of urban development and composition. The existence and evolvement of public street facilities within tourism areas reflect urban level of civilization and the development quality of space environment. The nature of public street facility is consistent with the nature of scenic spot environment. It has the characteristics of culture, continuance, diversity, adaptability and specificality and so on.

- The design features of the public street facilities within tourism areas can highlight the characteristics of the overall urban environment. By the pursuit of facility form, color and other visual effects, and usable functions, it can improve the artistic temperament of public space and shape a good city character. Meanwhile it can echo with philosophies of the city and meet its spiritual requirements. The existence of public street facilities in tourism areas bears the task of creating a humanistic and integrated environment space, and enriching our cultural life in city.

\section{REgiONAL DESIGN OF PUBliC STREET FACILITIES IN TOURISM AREAS}

\section{A. Basic Classification of Public Street Facilities in Tourism Areas}

The public street facility is an important part of urban public space. Starting from its functions and form characteristics, it can be classified as guided public street facility, lighting facility, service public street facility, barrierfree public street facility and recreational fitness public street facility. However, some tourism areas are not equipped with recreational fitness facilities. For example, a lot of tourism areas in Jinan have a strong historical and cultural atmosphere and the overall aura of tourism areas is full of antique charm.

\section{B. The Basic Requirements of Public Street Facilities in Tourism Areas}

First of all, the public street facilities in tourism areas have common characteristics and individuality, which are different and opposite from each other. Secondly, the similarities and differences of the public street facilities in tourism areas are interdependent and linked with one another. Thirdly, the similarities and differences of the public street facilities in tourism areas can be mutually transformed under certain conditions. For example, with respect to all environment facilities, the recreational facilities for children are of bright colors and individualized. Regardless of different types, functions and shapes, bright color of children's recreational facilities maybe is their common feature. It is a transformation with different evaluation standards and requirements. 


\section{The Significance of Regional Design of Street Public Facilities}

The regional design of public street facilities is an extraction and utilization of regional traditional historical and cultural elements which are different from regional natural landscape and traditional architectural form. Without specific form, it is historical and cultural sedimentation and accumulation of a city. So, the public street facility design is an extension of environmental space design. In fact, people and environment elements have been obviously put in a prominent position in design, which is consistent with the basic requirements of public street facility design. The uniqueness of public street facility design is that it should be carried out according to the cultural background, geographical environment, the urban scale, customs and humanity and other elements in the specific space. And then provide different solutions to the public street facilities with same functions, to make it consistent with environmental space better.

First, the regional design of public street facilities is considered as a special design to attract the attention of people, which could effectively guide and help people identify target object, spatial location and environmental characteristics in a specific environment, and people's environment for activities. The existence of pubic street facilities could give direct recognition and help. Second, the regional features of public street facilities could reflect the hidden historical and cultural connotation and humanistic contents, and reveal intrinsic cultural context and style of the times to the public.

In a sense, a region's history, cultures and folk customs can be reflected by the city environment and public street facilities in the specific tourism environment, so as to show the unique charm of the city. The information dissemination pattern of urban public street facility is constantly developed, enriched and integrated, and the extended products are also reflected in the connotation of public street facility.

\section{The Principle of Regional Design of Public Street Facilities in Tourism Areas}

1) The Principle of Reasonable Design: The reasonable design principle of public street facility in tourism areas is firstly expressed in the use of different materials, colors and expression techniques, different technologies, processes and processing methods in different types of pubic street facilities within scenic spots. It is realized through cooperation with enterprises and mass production, so design reasonability is the basic guarantee for public street facilities to achieve the functions. Secondly, people could understand the significance and use methods of these public street facilities once they approach them. People don't need to read instructions or have any psychological doubt in contact with the facilities.

2) The Principle of Integrity: Tourism area is an important part of city space environment, so the public street facilities within the area should also meet the needs of people for outdoor activities, and should be harmonious with the surrounding environment. The harmony is not just on surface color, shape and arrangement mode. The more important is to seek a harmony in spiritual level and deeper meaning.
Therefore, large facilities and small facilities should have their own characteristics, and they should be interdependent and mutually associated, and integrate their own individuality into the common system, showing the characteristics of unity and systematization.

3) The Principle of Culture: Whether a tourism area follows the culture principle has an important measurement value for the design of public street facilities within tourism area. It mainly contains the continuation of historical development and the reflection of background environment in urban development. The former, in terms of time, stresses to extract relevant elements or useful historical information from traditional public street facilities, and also adopts modern wisdom and elements. The later, in terms of region, treats the open space environment entirety of tourism area as the representative of the miniature of the urban residents' leisure life and urban scenes, which has a good guidance to the positioning and grasp of environmental style. Good public street facility design should not only have the practical functions, and its existence should also bring the sense of history, reflect modern culture and possess highly cultural connotation and aesthetic value. If our design lacks all-round considerations, and is full of personal ideas and concepts, the meaning of public street facilities will disappear.

4) The People-oriented Principle: The outdoor public space environment to people living in the urban environment for a long time is what sunshine and water are to plants in the dense forest. When there is such an environment space, and all in this specific environment are complete, they can slow down the rhythm of their life and work, and experience the comfort and ease that the nature brings to them. Mature cities tend to be more and more attractive than newly developed cities, for mature cities possess naturally formed outdoor space environment.

The public street facility design of tourism area should consider the use demand of the public, and put the element of people first. The existence of public street facilities in specific environment should highlight the demand of their users, rather than the purpose of itself. If the public street facilities in tourism area are over exaggerated, decorated and take precedence over the major one, they would bring inconvenience to users and go against the people-oriented principle. Tourism areas are places for people to relax, and they provide people with a free, unrestrained and relaxed environment to cultivate their taste. People participate in the activities in the scenic spot. In fact, they are pursuing and experiencing leisure life.

5) The Sustainable Green Ecological Principle: The public street facility of tourism area should adjust materials to local conditions, which could reduce unnecessary waste and show the unique features of the area through these materials. Thus, the materials in design could source from local existing materials fundamentally. Use different features of materials to build public street facilities. Natural materials have no harm to environment and man. After manufacturing and molding, they still possess own characteristics and also could reflect 
natural characteristics. Selecting appropriate materials has an important role in the representation of regional features of public street facilities in tourism areas. The selection of materials affects the atmosphere of facility space, and is associated with the expression and show of design creativity. Therefore, we should select materials of local features for public street facilities, to adapt to the atheistic habits of the local people, and further strengthen the regional identification and continuity of public street facilities in tourism area.

6) The Principle of Fitting Regional and Urban Development: Inherits and continues regional characteristics. It is the most direct and effective way to use regional features to create featured urban culture. We should make maximum efforts to protect the city's original architectural cultural heritage and remaining folk culture in urban public street facility design, and reasonably, harmoniously deal with the relationship of modernizing urban living facilities and preserving traditional scenes. Each place has its own way of supporting its own inhabitants, which means different regional culture could shape different characters. Specific regions have their unique urban cultures which are accumulated in its social and historical development.

\section{THE INSPIRATION FROM REGIONAL DESIGN OF PUBLIC STREET FACILITIES IN TOURISM AREAS}

The public street facilities of different styles reflect the similarities and differences of cultures in different times, regions and environments. Now the establishment, transformation and renovation of the tourism scenic spot are carried out continuously. Therefore, we should protect the integrity of the original historical building and public street facilities, and also integrate featured design elements, respect or adapt to existing facility look, temperament and characteristics. Thus, it can reflect the extension of historic culture and satisfy the requirement of high identification of local characteristics.

- The public street facilities and facilities pieces in tourism area are representative culture bearers. People could rapidly, directly understand the cultural characteristics of specific regions through shapes, colors and featured elements of facilities without spending a lot of time and energy. The update and development of tourism area are obvious. But its historical context is hidden in urban development. The connotation is not directly reflected. For the general open public space of the tourism area, the purpose of public street facilities we design is to awaken people memory on the culture context and regional features of this city, and thus extend the unique potential, charm and character of the whole city. The public street facility design of tourism area should not only provide functions, but also reflect regional features only belonging to their city and only reflecting the character of their city.

- The observation and interpretation of a city should look at the existence of the phenomena with a broad vision. People enjoy the city life, at the same time, read and experience the profound development of the city. Tourism area is a special space. The delightful public street facility design can properly combine functionality and interestingness into a whole, and can coordinate and be compatible with the artistry of tourism areas, extract and explore various elements of geographical features, and then apply them into environmental design, in order to avoid artificial damage and fragment of culture and historical characteristics. In addition, it pays attention to people's sense of belonging, reflecting the regional cultural characteristics of scenic spots. Anyway, for the development and perfection of public street facilities in tourism areas, we should not only pay attention to the embodiment of "quantity", but also the improvement and change of "quality", so that the existence of public street facilities could be reflected appropriately.

- The public street facilities in tourism areas are open and in a state of change, which are permeated with the construction and natural environment in the scenic area. The public street facilities in tourism areas are the bridges connecting the building and the nature in the scenic area, and are media for people to get close to nature. There are no clear boundaries among public street facilities, buildings and nature. They blend together and have the effect of transition to each other.

- The regional design of public street facilities is to demonstrate and develop environment characteristics of the tourism area. In this particular environment, for example, its powerful aura plays a pin-pointing role with its unique meaning. And it enriches people's physical and psychological needs with its unique shape, color, size, scale, texture decoration and so on. The fundamental purpose of the design is to service the public, and the participation of the public can be used to measure the design level of public street facilities. The participation degree and state of the public depends on each person in the specific environment, and also depends on whether there are freedom and diversity of multiple choices on public street facilities in the space.

- As an important part of urban public environment, the public street facilities within tourism area not only inherit and continue the city's history, shape the spiritual image of the city, and improve the living environment, but also have the functions of sightseeing, education, exhibition and guidance. What's more, they also have the effect of shaping featured landscape and reflecting regional culture atmosphere of the city. The public street facility design of tourism area is associated with many considerations of designers and users, and the understanding of unique cultural connotation of the city. The public street facilities in tourism area could meet people's spiritual demands, and give citizens sense of pride and belonging to the city and intimacy. When the public street facilities are improved, the people will accept everything in this environment, and have a sense of identity and satisfaction. 


\section{REFERENCES}

[1] Yang Guang. Public Arts in City. Urban Environment Design, 2009.

[2] Li Zhu. Urban Landscape Design and Context Continuation. Wuhan University of Technology, 2006.

[3] Lu Shajun. Humanized Design of Urban Outdoor Furniture. Journal of Jiangnan University, 2005.

[4] Guo Xiyan. Applied Research on Regional Culture in Landscape Design. Fujian Normal University, 2008.

[5] Li Qiong. Study on Landscape Pattern of Urban Public Leisure Space. Zhejiang University, 2006.

[6] Wang Nan, Chen Mei. Analysis of the Harmonious Design of Public Environmental Facilities in City Park. Shanghai Business, 2009.

[7] Wei Xiaohui. Humanistic Interpretation of Urban Public Environment Facility Design. Science Studies, 2009. 